\title{
Potential role of stem cells in management of COPD
}

This article was published in the following Dove Press journal:

International Journal of COPD

25 March 2010

Number of times this article has been viewed

Tillie L Hackett ${ }^{1,2}$

Darryl A Knight ${ }^{1,2}$

Don D Sin ${ }^{1,3}$

'UBC James Hogg Research Centre, Heart and Lung Institute, St Paul's Hospital, Vancouver, BC, Canada, V6Z IY6; ' ${ }^{2}$ Department of Anesthesiology, Pharmacology and Therapeutics, ${ }^{3}$ Department of Medicine, University of British Columbia, Vancouver, BC Canada
Correspondence: DD Sin

UBC James Hogg Research Centre,

Heart and Lung Institute, St. Paul's

Hospital, Room 166, 108I Burrard Street,

Vancouver, BC, Canada V6Z IY6

Tel +6046822344 extn 68395

Fax +604806 835I

Email don.sin@hli.ubc.ca
Abstract: Chronic obstructive pulmonary disease (COPD) is a worldwide epidemic affecting over 200 million people and accounting for more than three million deaths annually. The disease is characterized by chronic inflammation of the airways and progressive destruction of lung parenchyma, a process that in most cases is initiated by cigarette smoking. Unfortunately, there are no interventions that have been unequivocally shown to prolong survival in patients with COPD. Regeneration of lung tissue by stem cells from endogenous and exogenous sources is a promising therapeutic strategy. Herein we review the current literature on the characterization of resident stem and progenitor cell niches within the lung, the contribution of mesenchymal stem cells to lung regeneration, and advances in bioengineering of lung tissue.

Keywords: COPD, stem cell therapy, epithelial repair, regenerative medicine

\section{Introduction}

Chronic obstructive pulmonary disease (COPD) is a worldwide epidemic affecting an estimated 210 million people and accounting for more than three million deaths annually. ${ }^{1}$ Over the next 20 years, the World Health Organization expects total COPD mortality to more than double. In China alone, three million men and women are expected to die from COPD by the year 2030 if current cigarette and biomass exposure trends continue. ${ }^{2}$ Unfortunately, aside from supplemental domiciliary oxygen for the small number of patients who demonstrate resting arterial hypoxemia and smoking cessation for continued smokers, there are no interventions that have been unequivocally shown to prolong survival in patients with $\mathrm{COPD}^{3}$ and no therapies that can fully restore the lost lung function associated with COPD. As COPD is characterized by loss of lung tissue and remodeling of the airways, there is growing enthusiasm for using stem and progenitor cells to regenerate healthy parenchymal and airway cells and restore lung function in patients with COPD. In this paper, we review the rationale and examine the clinical and animal evidence for the use of stem and progenitor cell therapy in COPD.

\section{Mechanisms of structural cell damage in COPD}

To understand the rationale for stem and progenitor cell therapy in COPD, it is important to examine first the prevailing theories of COPD pathogenesis that underpin regenerative medicine. Morphologically, COPD is characterized by two distinct but related pathologic features, ie, bronchiolitis involving predominantly the small airways (airways less than $2 \mathrm{~mm}$ in diameter) and emphysema. ${ }^{4}$ Emphysema is characterized by dilatation and destruction of lung tissue beyond the terminal bronchioles. 
The centriacinar form of emphysema is characterized by tissue destruction of the respiratory bronchioles and occurs most frequently in cigarette smokers. Panacinar emphysema, on the other hand, is characterized by destruction of the entire acinar unit and occurs largely in the setting of alpha-1 antitrypsin deficiency. ${ }^{4}$ The key pathophysiologic changes underlying airflow limitation in COPD include the loss of elastic lung recoil pressure due to the destruction of alveolar septa and terminal bronchioles (emphysema), increased airflow resistance due to airway wall remodeling (ie, thickening of small airway wall) and mucoid impaction of the airway lumen. ${ }^{4}$ In addition, there is growing evidence that endothelial dysfunction and vascular remodeling initiated by vascular endothelial growth factor-mediated apoptosis of endothelial cells may also contribute to disease progression in COPD. ${ }^{5}$

Although there have been tremendous advances in our understanding of COPD pathobiology over the past two decades, the exact pathologic mechanisms by which emphysema and airway remodeling occur in COPD remain largely a mystery. One of the leading theories is the "inflammatory hypothesis". Proponents argue that in certain (genetically) susceptible individuals, lung inflammation, which occurs in response to environmental triggers such as air pollution and cigarette smoke, changes from a "normal" response to an abnormal one, characterized by excess innate and adaptive immunity, at some point during the exposure. ${ }^{6}$ This abnormal inflammatory response is further exaggerated during exacerbations. Two processes considered to be pathogenically important in this abnormal inflammatory response are proteolytic ${ }^{7}$ and oxidant stress $^{8}$ driven by the influx of inflammatory cells, ie, neutrophils, macrophages (innate response), and lymphocytes (adaptive response). ${ }^{9}$ Interestingly, once the inflammatory changes are firmly established in the lungs, the removal of the environmental trigger such as cigarette smoke does not fully abrogate the abnormal inflammatory response observed in the airways. Indeed, smokers who discontinue smoking continue to demonstrate airway inflammation. ${ }^{10}$

\section{Mechanisms of cellular aging and senescence in COPD}

Another emerging hypothesis relates to accelerated cellular aging, or senescence that results in a series of perturbations in cell morphology and function, ultimately culminating in cell cycle arrest. ${ }^{11,12}$ The molecular and cellular mechanisms associated with cellular senescence include DNA damage, ${ }^{13}$ abnormal DNA repair, ${ }^{14}$ impairment of epigenetic modifications of DNA, ${ }^{15}$ telomere shortening, ${ }^{16}$ and free radical formation and protein damage. ${ }^{17}$

In COPD patients with emphysema, several alterations in structural cells related to aging and senescence have been demonstrated. For example, lung fibroblasts from patients with emphysema have been shown to stain positive for senescence-associated $\beta$-galactosidase, a marker of cellular senescence, and demonstrate reduced proliferative capacity compared with fibroblasts obtained from healthy smokers. ${ }^{18}$ It has also been shown that Type II alveolar and endothelial cells from emphysematous patients have increased expression of cyclin-dependent kinase inhibitors $\mathrm{p} 16^{\mathrm{INK} 4 \mathrm{a}}$ and p $21^{\text {Wafl/CIP1 }}$ which can both induce senescence. ${ }^{19}$

Although there is little understanding of epigenetic modifications in relation to specific genes in COPD, global acetylation of histone $\mathrm{H} 3$ has been detected in the lungs of exsmokers with COPD.$^{20}$ In addition, the histone deacetylases, histone deacetylase (HDAC) 2 and Sirtuin 1, which act on histone residues to mediate DNA silencing, have been shown to be decreased in the lungs of COPD patients compared with healthy smokers who had not developed COPD. ${ }^{21,22}$ The reduced expression of Sirtuin 1 in COPD patients was shown to be due to post-translational oxidative modification by cigarette smoke. ${ }^{21}$ As Sirtuin 1 is important for nuclear factor (NF)-kB-dependent transcription and cell survival to tumor necrosis factor (TNF), a reduction in Sirtuin 1 would lead to increased acetylation of histones and enhanced inflammation in response to cigarette smoke.

Finally, in somatic cells, telomeres shorten with every cell cycle and when they reach a critical length, senescence is induced. Telomeres are thus a good biomarker of cellular aging. Several studies have demonstrated shorter telomeres in leukocytes in current smokers when compared with exand nonsmokers, ${ }^{23,24}$ and Tsuji et al showed that patients with COPD had shorter telomeres in Type II epithelial and endothelial cells compared with telomeres from smoking and nonsmoking controls. ${ }^{19}$ In contrast, Muller et al did not find a significant difference in telomere length of lung fibroblasts between individuals with and without emphysema. ${ }^{18}$ However, in both studies, the authors found that other biomarkers of senescence were upregulated and overexpressed. In terms of systemic aging in COPD we have recently demonstrated that COPD patients have shorter telomeres in their peripheral circulation than do healthy people and their telomere length decreases with worsening lung function. We further demonstrated that telomere length was related to surfactant protein-D, a lung specific biomarker, but not to nonspecific systemic biomarkers of inflammation such as 
C-reactive protein and interleukin-6, raising the possibility that the generalized aging process may be driven by the lung disease. ${ }^{25}$ Collectively, there appears to be sufficient evidence to suggest that resident structural cells within the lungs and lymphocytes within the systemic circulation of COPD patients exhibit markers of cellular senescence and accelerated aging, which is potentially detrimental to normal lung repair.

\section{Mechanisms of lung repair}

Theoretically, if the reparative and regenerative processes in the lungs can keep up with the destructive, inflammatory, or apoptotic processes, then lung homeostasis can be maintained, leading to the preservation of normal tissue and function. Following epithelial injury, the airway epithelium begins to repair almost immediately. At the wound edge, the (undamaged) epithelial cells de-differentiate and migrate to "cover up" the wounded area and release a variety of proinflammatory cytokines and growth factors to attract proteins and cells needed for restoration of the extracellular matrix, which is crucial for normal wound repair. Once this occurs, re-epithelialization can proceed.

The adult human lung comprises various trophic units which are each lined by specialized types of airway epithelia. ${ }^{26}$ The ability of the lung to repair itself in the setting of injury is determined by the molecular events that mobilize the resident stem and progenitor cells within each of the trophic units. Stem cells and progenitors are similar in that they both proliferate and give rise to differentiated cells but only stem cells are capable of self-renewal. ${ }^{27}$ The reader is referred to Figure 1 for the putative stem and progenitor cell niches within the human lung.

\section{Resident stem cells within the lung}

In contrast to dermal and intestinal epithelia, which are highly proliferative and rapidly renewing, the turnover of the airway epithelium is extremely slow unless injured. ${ }^{28}$ Each of the tracheal, bronchial, and alveolar regions within the lung has a distinct resident stem or progenitor cell population which possesses unique cellular physiologic properties. To date, several cells within the trachea and bronchial tissue have been reported to be enriched for stem/progenitor cell activity including cytokeratin 5/14-expressing basal cells, secretory (Clara) cells, cells residing in submucosal glands, and neuroepithelial bodies (NEB). ${ }^{29-33}$ A more recent study indicates that cytokeratin 5/14 expressing basal cells can self-renew and also give rise to new ciliated Clara and secretory cells following epithelial injury. ${ }^{34}$ We have also demonstrated that within human airways the basal cell population contains a side population (SP) of cells, which are characterized by the ability to efflux actively the DNA binding dye, Hoescht 33342. ${ }^{35}$ As with other epithelial tissues such as in mammary glands, ${ }^{36,37}$ the eye, ${ }^{38}$ and the skin, ${ }^{39}$ SP cells within the airways are rare, making up less than $0.1 \%$ of the total epithelial cell population. We further demonstrated that a single SP cell had the potential to differentiate and form air-liquid interface cultures containing basal, ciliated, and secretory cells. Consistent with these findings, Giangreco et al have demonstrated using an aggregation chimera mouse that in normal and moderately injured airways, single randomly distributed progenitor cells are capable of maintaining epithelial homeostasis. ${ }^{40}$ On the other hand, repair following severe injury resulted from large clonal cell patches associated with stem cell niches residing in neuroendocrine bodies (NEB) and bronchioalveolar duct junctions (BADJ). ${ }^{40}$ The existence of Clara cells expressing Scgb1al (Secretoglobin 1a1, also known as CC10 or CCSP) which function as stem cells in the NEB microenvironment of the bronchiolar epithelium and BADJ have previously been demonstrated by Giangreco and colleagues. ${ }^{41}$ An important finding of this study was that repair mediated through activation of local stem cells led to a loss of progenitor cell diversity. ${ }^{40}$

Within whole mouse lung tissue digests, Summer et al demonstrated a population of SP cells that were sca-1-positive and heterogeneous for CD45 expression, and comprised $0.03 \%-0.07 \%$ of all lung cells. ${ }^{42,43}$ This group went on to demonstrate that sca-1-positive, CD45 negative SP cells from mouse lung has a molecular profile similar to NEB-associated CCSP expressing Clara cells. ${ }^{43}$ The BADJ has also been proposed to harbor a subset of Clara cells expressing an alveolar Type II marker surfactant protein C. As these cells proliferate following injury, it was proposed that these cells gave rise to bronchiolar and alveolar cells in vivo. ${ }^{44}$ However, Rawlins et al using mouse strains with cell lineage labeling, have recently demonstrated that $\mathrm{Scgbla} 1$ and surfactant protein $\mathrm{C}$ expressing cells in mice do not function as bronchioalveolar stem cells. ${ }^{45}$ They also demonstrated that specific populations of Clara cells were transiently amplifying progenitor cells for the bronchus but not alveoli. They showed that alveolar Type I cells are maintained only by alveolar Type II cells (regardless of their Scgbla expression status).

Unfortunately, the field has limited knowledge of the phenotypes of stem/progenitor cells within each trophic unit of the human lung, due to the technical difficulty of sampling and the paucity of available markers for identification. Thus, a fundamental understanding of each of the stem cell niches and the molecular signals that enhance repair in each of the 

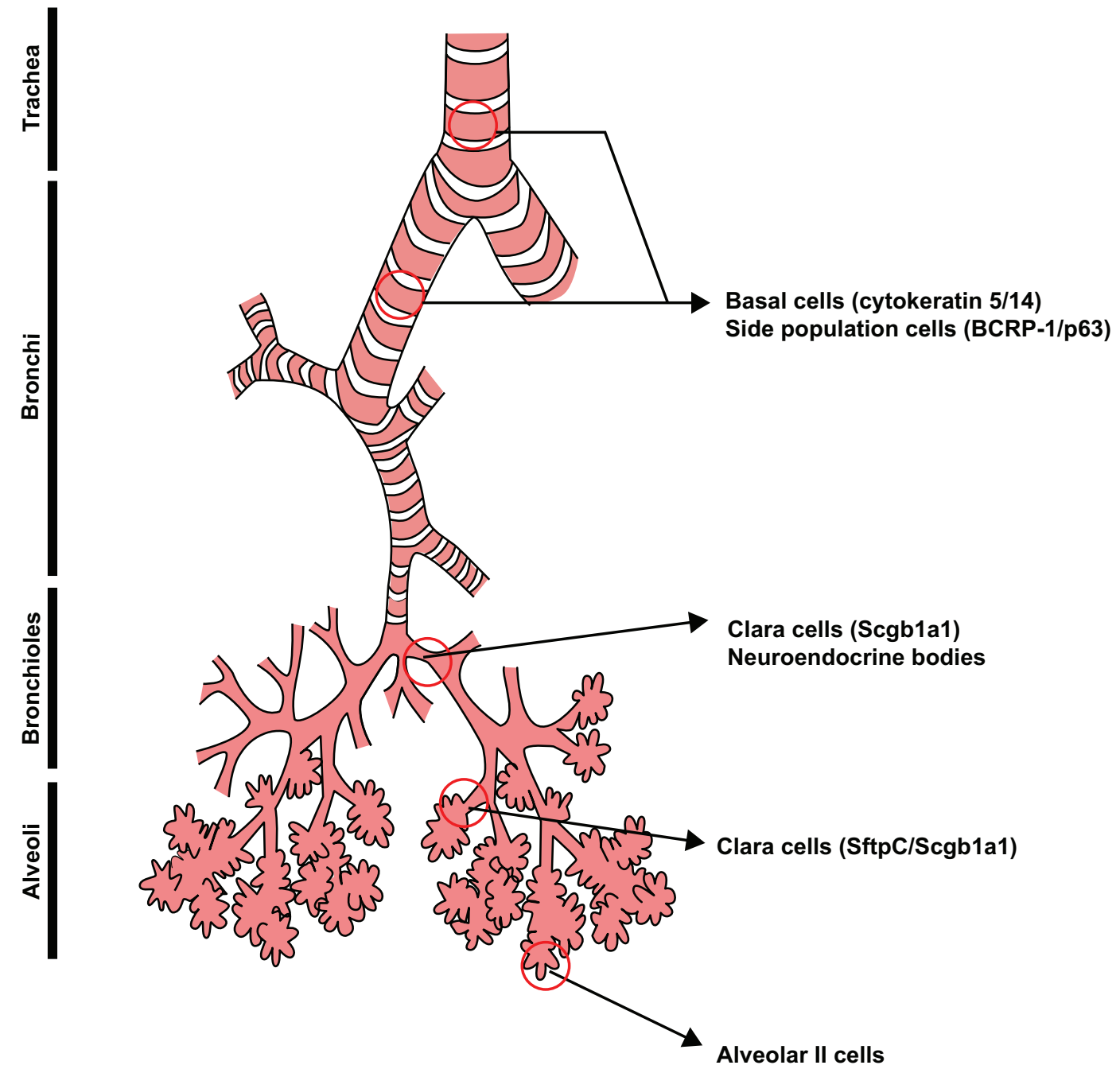

Figure I Illustration of putative stem/progenitor cells which have been demonstrated within the four trophic regions of the human lung, ie, trachea, bronchi, bronchioles and alveoli. Reprinted with permission of the American Thoracic Society. Copyright @ 2008, American Thoracic Society. X, Engelhardt JF. The glandular stem/progenitor cell niche in airway development and repair. Proc Am Thorac Soc. 2008;5(6):682-688.

tropic units of the lung is required for future development of regenerative therapies.

\section{Potential mechanisms to enhance resident stem cell regeneration}

As resident stem cells within the airways have the capacity to regenerate tissue following damage, one possible therapeutic option could be to enhance resident stem cell activation. The angiogenic factor, fibroblast growth factor-2 (FGF-2), is essential for normal lung development and branching morphogenesis. In canine models of emphysema, FGF-2 has been shown to increase pulmonary blood flow to the damaged lung, leading to recovery of pulmonary function. ${ }^{46}$ However, in this same study, FGF-2 did not regenerate parenchymal tissue or induce alveolar septation.
Adrenomedullin, a potent vasodilator peptide, has been shown to significantly increase lung volume, static lung compliance, and mean linear intercept of alveolar tissue in mouse lungs treated with elastase, suggesting that it protects against parenchymal destruction related to excess proteolytic activity in the lungs. ${ }^{47}$ Treatment with adrenomedullin was associated with increased numbers of mononuclear cells and sca-1 positive cells in circulating blood, and increased numbers of bone marrow derived cells within the elastasetreated lung. The authors concluded that adrenomedullin may improve emphysema by mobilizing bone marrow cells and protecting alveolar epithelia and endothelial cells against tissue destruction.

All-trans-retinoic acid (ATRA) is an analogue of vitamin A and plays an important regulatory role in cell development, differentiation, and homeostasis. There are two types of 
retinoid receptors, ie, retinoic acid receptors and retinoid $\mathrm{X}$ receptors. There are also three different isoforms of retinoic acid receptor: $\alpha, \beta$, and $\gamma$, which have different regulatory roles in alveolar development. ${ }^{48,49} \mathrm{RAR} \gamma$, for instance, is necessary for alveolar formation in mice during the first 28 days following birth. Tepper et al demonstrated that injection of ATRA nine weeks after porcine elastase-induced emphysema in rats showed no progression in elastase-induced airway destruction compared with elastase-treated controls. ${ }^{50}$ This was associated with small but significant changes in lung volume, but not lung density as measured by computed tomography (CT). However, Fujita and colleagues found using an elastase-induced emphysema model and a tumour necrosis factor (TNF)-alpha in transgenic mouse that daily treatment with intraperitoneal ATRA injections for 12 days following induction of emphysema had no significant differences in lung histology compared with controls. ${ }^{51}$ These studies indicated that the beneficial effects of ATRA may be species-specific. Further Ishizawa et al found that the combination of granulocyte-colony stimulating factor and ATRA had an additive effect in decreasing emphysema induced by elastase, indicating that mobilization of bone marrow cells could potentially play a role in lung regeneration after injury. ${ }^{52}$ In humans, a small study by Paiva et al demonstrated that patients with moderate to severe COPD had reduced concentrations of circulating vitamin A levels and that supplementation of vitamin A could lead to improvements in lung function. ${ }^{53}$ Another small study involving 20 patients with moderate to severe COPD evaluated the potential for ATRA. ${ }^{54}$ In this study, patients were treated with either ATRA (50 mg/m²/day) or placebo for 12 weeks, followed by a 12 -week crossover phase. The trial demonstrated that although ATRA was well tolerated, it had no effect in reversing emphysema. The FORTE (Feasibility of Retinoids for the Treatment of Emphysema) study further evaluated the potential efficacy of retinoid therapy in a multicenter trial. ${ }^{55}$ Although there was a dose- and time-dependent improvement in diffusing capacity, CT density mark score, and quality of life scores among subjects treated with ATRA, there were no definitive clinical benefits that could be observed with ATRA therapy. These data suggest that future studies focused on the biologic activity of ATRA in emphysematous patients requires further investigation.

\section{Bioengineering of lung tissue}

Both embryonic and adult stem cells in vitro can be induced to differentiate into airway and alveolar epithelial cells. However, engraftment following systemic administration is rare, fraught with many technical impediments, and the cells which do engraft in tissues often demonstrates a lack of relevant biologic responses. Thus the recent focus has been to use bioengineered three-dimensional matrices or artificial scaffolds to generate functional lung tissue in vitro and in vivo. These efforts have been previously successful in growing and regenerating skin, blood vessels, bone, and cartilage. With respect to the lung, MSCs isolated from amniotic fluid, umbilical cord blood, adipose tissue, or bone marrow have been used to generate tracheal cartilage using biosynthetic scaffolds in order to repair congenital tracheal defects in rodent models and more recently in human clinical trials. ${ }^{56-58}$ Macchiarini et al were able to use a patient's epithelial cells and MSC-derived chondrocytes to generate a bioengineered trachea, which after engraftment provided a functional airway without the requirement for immunosuppressive drugs. ${ }^{59}$

However, recreating the three-dimensional architecture of the lung parenchyma via bioengineering represents a substantial technical challenge. Therefore current murine studies have focused on understanding lung development with the hope that this knowledge (and technology) can be transferred to patients who require "lung repair". These studies are utilizing mixed fetal lung cells, three-dimensional scaffold proteins, and growth factors such as fibroblast growth factor in vitro and in vivo to develop functional lung parenchymal tissue. In recent studies, the addition of gelatin or matrigel sponges imbedded with fetal lung cells in rodent lung repair models have demonstrated branching and epithelial structures reminiscent of alveolar architecture. ${ }^{60,61}$ Furthermore, in lung volume reduction models in rats, adipose-derived MSCs cultured on polyglycolic acid sheets applied to the wound edge have been demonstrated to accelerate alveolar and vascular regeneration. ${ }^{62}$ However, few studies have demonstrated the usefulness of bone marrow-derived cells compared with resident lung stem cells in these experiments and if the outcomes of tissue functionality are different with diverse stem cell sources. Thus, we still require future studies to develop our understanding of bioengineered lung tissue to meet clinical needs in COPD.

\section{Exogenous stem or progenitor cells}

Early studies using bleomycin or radiation-induced lung injury demonstrated the recruitment and engraftment of bone marrow-derived cells within the lung. ${ }^{63-66}$ However, later studies using lineage markers have demonstrated no evidence of pulmonary repopulation via bone marrowderived cells. ${ }^{67,68}$ Many variables of how exogenous stem cells may be recruited and engrafted as functional epithelial 
cells are still left unanswered. These include their route of administration, the sources of stem cells and correct phenotype to administer, and the signals required from the lung for recruitment and engraftment of exogenous stem cells.

\section{Mesenchymal stem cells and immune modulators}

Mesenchymal stem cells (MSCs) are nonhematopoietic stem cells of mesodermal origin, with the capacity to differentiate into both mesenchymal and nonmesenchymal lineages. MSCs are found primarily in the bone marrow of adults and give rise to blood, skeletal muscle, vascular, and connective tissues throughout the body. Postnatally, bone marrow MSC can be isolated from adipose tissue, liver, synovial membrane, teeth, and tendons. In particular, MSCs are easily isolated from a small aspirate of bone marrow and can be expanded with high efficiency. MSCs have great potential in clinical therapy because they express intermediate to low levels of HLA Class I, low levels of HLA Class II, and low levels of costimulatory molecules to avoid self-recognition by the immune system. ${ }^{69}$ In immunocompetent patients, MSCs have also been demonstrated to suppress allogeneic T-cell proliferation and evade alloreactive recognition. ${ }^{70}$ The immunomodulatory properties of MSCs are thought to involve the secretion of soluble mediators and cell-cell contact inhibition; however, the exact mechanisms of action are unclear. ${ }^{71}$ In an acute lung injury model in mice using bleomycin, systemic administration of MSCs has been demonstrated to decrease the accumulation of collagen, fibrosis and levels of matrix metalloproteinases. ${ }^{68}$ The proposed mechanism of action for these findings was the secretion of interleukin-1 receptor antagonist by the MSCs. ${ }^{72}$ In endotoxin-induced lung injury models, intratracheal administration of MSCs has been demonstrated to decrease mortality, tissue inflammation, and concentrations of inflammatory mediators (in particular TNF $\alpha$ and MIP $1 \beta$ ) within bronchoalveolar lavage fluid. ${ }^{73}$ Recent studies suggest that the release of angiopoietin-1 by MSCs is potentially another important mechanism in stabilizing the endothelial fluid leak and maintaining alveolar-capillary barrier function in an endotoxin injury model. ${ }^{74,75}$

\section{Clinical trials of MSCs}

Autologous and allogeneic MSCs are currently being tested in clinical trials for a variety of diseases including Crohn's disease, multiple sclerosis, diabetes mellitus and end-stage liver disease, and to prevent transplant rejection and restore left ventricular function in patients with congestive heart failure. ${ }^{76}$ An open-label Phase II trial utilizing Prochymal ${ }^{\circledR}$, an allogenic MSC infusion in patients with severe Crohn's disease, who were unresponsive to corticosteroids, infliximab (anti-TNF antibody), and other immunosuppressive therapies, has recently been completed. The study reported significant improvements in symptoms as assessed by the Crohn's disease activity index (CDAI). This has led to the approval by the Food and Drug Administration for a Phase III doubleblind, placebo-controlled trial of this therapy for the treatment of Crohn's disease. ${ }^{77}$

In 2008, Osiris therapeutics initiated a multi-center, double-blind, placebo-controlled Phase II clinical trial of Prochymal in patients with moderate to severe COPD. At the six-month interim report, the trial contained 62 patients (58\% men). The age range of the subjects was from 47 to 80 years, and 23 of the patients had moderate and 39 had severe disease. The important findings of the interim report were that Prochymal was safe and significantly reduced systemic inflammation in these patients compared with those receiving placebo, as determined by circulating levels of C-reactive protein. ${ }^{78}$ However Prochymal did not significantly alter lung function in these patients. ${ }^{78}$ Final completion of this two-year trial will provide new insights in the potential utility of MSCs in treating patients with COPD.

\section{Conclusion}

Despite significant progress in our understanding of lung stem cells and their functional capacities over the past decade, much remains unknown about the processes involved in lung repair. Accumulating data from both animal models and clinical trials suggest that adult-derived stem cells may provide potential therapeutic strategies for lung repair in COPD. Pivotal clinical trials are currently underway, which in a few years will provide major insights on the utility of using stem and progenitor cells as therapeutic agents in COPD.

\section{Acknowledgements}

This research was supported by the Canadian Institutes of Health Research. TLH is a recipient of a CIHR/CLA/GSK, IMPACT strategic training and Michael Smith Foundation for Health Research post doctoral fellowship. DDS and DAK are Michael Smith Foundation for Health Research senior scholars and holders of the Canada Research Chairs.

\section{Disclosures}

The authors report no conflicts of interest in this work. 


\section{References}

1. World Health Organization. Chronic Obstructive Pulmonary Disease (COPD) 2009. Fact sheet No 315.

2. Lin HH, Murray M, Cohen T, Colijn C, Ezzati M. Effects of smoking and solid-fuel use on COPD, lung cancer, and tuberculosis in China: A time-based, multiple risk factor, modelling study. Lancet. 2008;372(9648):1473-1483.

3. Sin DD, McAlister FA, Man SF, Anthonisen NR. Contemporary management of chronic obstructive pulmonary disease: Scientific review. JAMA. 2003;290(17):2301-2312.

4. Hogg JC. Pathophysiology of airflow limitation in chronic obstructive pulmonary disease. Lancet. 2004;364(9435):709-721.

5. Siafakas NM, Antoniou KM, Tzortzaki EG. Role of angiogenesis and vascular remodeling in chronic obstructive pulmonary disease. Int J Chron Obstruct Pulmon Dis. 2007;2(4):453-462.

6. Barnes PJ. Chronic obstructive pulmonary disease *12: New treatments for COPD. Thorax. 2003;58(9):803-808.

7. Shapiro SD. Proteinases in chronic obstructive pulmonary disease. Biochem Soc Trans. 2002;30(2):98-102.

8. MacNee W. Pulmonary and systemic oxidant/antioxidant imbalance in chronic obstructive pulmonary disease. Proc Am Thorac Soc. 2005;2(1):50-60.

9. Curtis JL, Freeman CM, Hogg JC. The immunopathogenesis of chronic obstructive pulmonary disease: Insights from recent research. Proc Am Thorac Soc. 2007;4(7):512-521.

10. Willemse BW, ten Hacken NH, Rutgers B, Lesman-Leegte IG, Postma DS, Timens W. Effect of 1-year smoking cessation on airway inflammation in COPD and asymptomatic smokers. Eur Respir J. 2005;26(5):835-845.

11. Ito K, Barnes PJ. COPD as a disease of accelerated lung aging. Chest. 2009;135(1):173-180.

12. Karrasch S, Holz O, Jorres RA. Aging and induced senescence as factors in the pathogenesis of lung emphysema. Respir Med. 2008;102(9):1215-1230.

13. von Zglinicki T, Burkle A, Kirkwood TB. Stress, DNA damage and ageing-an integrative approach. Exp Gerontol. 2001;36(7):1049-1062.

14. Lou Z, Chen J. Cellular senescence and DNA repair. Exp Cell Res. 2006;312(14):2641-2646.

15. Fraga MF, Agrelo R, Esteller M. Cross-talk between aging and cancer: The epigenetic language. Ann N Y Acad Sci. 2007;1100:60-74.

16. Boukamp P. Ageing mechanisms: The role of telomere loss. Clin Exp Dermatol. 2001;26(7):562-565.

17. Friguet B. Oxidized protein degradation and repair in ageing and oxidative stress. FEBS Lett. 2006;580(12):2910-2916.

18. Muller KC, Welker L, Paasch K, et al. Lung fibroblasts from patients with emphysema show markers of senescence in vitro. Respir Res. 2006;7:32.

19. Tsuji T, Aoshiba K, Nagai A. Alveolar cell senescence in patients with pulmonary emphysema. Am J Respir Crit Care Med. 2006;174(8):886-893.

20. Szulakowski P, Crowther AJ, Jimenez LA, et al. The effect of smoking on the transcriptional regulation of lung inflammation in patients with chronic obstructive pulmonary disease. Am J Respir Crit Care Med. 2006;174(1):41-50.

21. Rajendrasozhan S, Yang SR, Kinnula VL, Rahman I. SIRT1, an antiinflammatory and antiaging protein, is decreased in lungs of patients with chronic obstructive pulmonary disease. Am J Respir Crit Care Med. 2008;177(8):861-870.

22. Ito K, Ito M, Elliott WM, et al. Decreased histone deacetylase activity in chronic obstructive pulmonary disease. $N$ Engl $J$ Med. 2005;352(19):1967-1976.

23. Valdes AM, Andrew T, Gardner JP, et al. Obesity, cigarette smoking, and telomere length in women. Lancet. 2005;366(9486):662-664.

24. Morla M, Busquets X, Pons J, Sauleda J, MacNee W, Agusti AG. Telomere shortening in smokers with and without COPD. Eur Respir J. 2006;27(3):525-528.
25. Mui TS, Man JM, McElhaney J, et al. Telomere length and chronic obstructive pulmonary disease: Evidence of accelerated aging. $J \mathrm{Am}$ Geriatr Soc. 2009;57(12):2372-2374.

26. Liu X, Engelhardt JF. The glandular stem/progenitor cell niche in airway development and repair. Proc Am Thorac Soc. 2008;5(6): 682-688.

27. Lajtha LG. Stem cell concepts. Differentiation. 1979;14(1-2): 23-24.

28. Kotton DN, Summer R, Fine A. Lung stem cells: New paradigms. Exp Hematol. 2004;32(4):340-343.

29. Breuer R, Christensen TG, Lucey EC, Stone PJ, Snider GL. An ultrastructural morphometric analysis of elastase-treated hamster bronchi shows discharge followed by progressive accumulation of secretory granules. Am Rev Respir Dis. 1987;136(3):698-703.

30. Hong KU, Reynolds SD, Watkins S, Fuchs E, Stripp BR. In vivo differentiation potential of tracheal basal cells: Evidence for multipotent and unipotent subpopulations. Am J Physiol Lung Cell Mol Physiol. 2004;286:L643-L649.

31. Hong KU, Reynolds SD, Watkins S, Fuchs E, Stripp BR. Basal cells are a multipotent progenitor capable of renewing the bronchial epithelium. Am J Pathol. 2004;164:577-588.

32. Hong KU, Reynolds SD, Giangreco A, Hurley CM, Stripp BR. Clara cell secretory protein-expressing cells of the airway neuroepithelial body microenvironment include a label-retaining subset and are critical for epithelial renewal after progenitor cell depletion. Am J Respir Cell Mol Biol. 2001;24:67-81.

33. Reynolds SD, Giangreco A, Power JH, Stripp BR. Neuroepithelial bodies of pulmonary airways serve as a reservoir of progenitor cells capable of epithelial regeneration. Am J Pathol. 2000;156(1):269-278.

34. Rock JR, Onaitis MW, Rawlins EL, et al. Basal cells as stem cells of the mouse trachea and human airway epithelium. Proc Natl Acad Sci US A. 2009;106(31):12771-12775.

35. Hackeff TL, Shaheen F, Johnson A, et al. Characterization of side population cells from human airway epithelium. Stem Cells. 2008;26(10):2576-2585.

36. Alvi A, Clayton H, Joshi C, et al. Functional and molecular characterisation of mammary side population cells. Breast Cancer Res. 2003;5(1): $\mathrm{R} 1-\mathrm{R} 8$.

37. Smith GH, Chepko G. Mammary epithelial stem cells. Microsc Res Tech. 2001;52:190-203.

38. Bhattacharya S, Jackson JD, Das AV, et al. Direct identification and enrichment of retinal stem cells/progenitors by Hoechst dye efflux assay. Invest Ophthalmol Vis Sci. 2003;44(6):2764-2773.

39. Redvers RP, Li A, Kaur P. Side population in adult murine epidermis exhibits phenotypic and functional characteristics of keratinocyte stem cells. Proc Natl Acad of Sci U S A. 2006;103(35):13168-13173.

40. Giangreco A, Arwert EN, Rosewell IR, Snyder J, Watt FM, Stripp BR. Stem cells are dispensable for lung homeostasis but restore airways after injury. Proc Natl Acad Sci U S A. 2009;106(23):9286-9291.

41. Giangreco A, Reynolds SD, Stripp BR. Terminal bronchioles harbor a unique airway stem cell population that localizes to the bronchoalveolar duct junction. Am J Pathol. 2002;161(1):173-182.

42. Summer R, Kotton DN, Sun X, Ma B, Fitzsimmons K, Fine A. Side population cells and Bcrp1 expression in lung. Am J Physiol Lung Cell Mol Physiol. 2003;285(1):L97-L104.

43. Reynolds SD, Shen H, Reynolds PR, et al. Molecular and functional properties of lung SP cells. Am J Physiol Lung Cell Mol Physiol. 2007;292(4):L972-83.

44. Kim CF, Jackson EL, Woolfenden AE, et al. Identification of bronchioalveolar stem cells in normal lung and lung cancer. Cell. 2005;121(6):823-835.

45. Rawlins EL, Okubo T, Xue Y, et al. The role of Scgbla1+ Clara cells in the long-term maintenance and repair of lung airway, but not alveolar, epithelium. Cell Stem Cell. 2009;4(6):525-534.

46. Morino S, Nakamura T, Toba T, et al. Fibroblast growth factor-2 induces recovery of pulmonary blood flow in canine emphysema models. Chest. 2005;128(2):920-926. 
47. Murakami S, Nagaya N, Itoh T, et al. Adrenomedullin regenerates alveoli and vasculature in elastase-induced pulmonary emphysema in mice. Am J Respir Crit Care Med. 2005;172(5):581-589.

48. Massaro GD, Massaro D, Chambon P. Retinoic acid receptor-alpha regulates pulmonary alveolus formation in mice after, but not during, perinatal period. Am J Physiol Lung Cell Mol Physiol. 2003;284(2): L431-L433.

49. McGowan S, Jackson SK, Jenkins-Moore M, Dai HH, Chambon P, Snyder JM. Mice bearing deletions of retinoic acid receptors demonstrate reduced lung elastin and alveolar numbers. Am J Respir Cell Mol Biol. 2000;23(2):162-167.

50. Tepper J, Pfeiffer J, Aldrich M, et al. Can retinoic acid ameliorate the physiologic and morphologic effects of elastase instillation in the rat? Chest. 2000;117(5 Suppl 1):242S-244S.

51. Fujita M, Ye Q, Ouchi H, et al. Retinoic acid fails to reverse emphysema in adult mouse models. Thorax. 2004;59(3):224-230.

52. Ishizawa K, Kubo H, Yamada M, et al. Bone marrow-derived cells contribute to lung regeneration after elastase-induced pulmonary emphysema. FEBS Lett. 2004;556(1-3):249-252.

53. Paiva SA, Godoy I, Vannucchi H, Favaro RM, Geraldo RR, Campana AO. Assessment of vitamin A status in chronic obstructive pulmonary disease patients and healthy smokers. Am J Clin Nutr. 1996;64(6):928-934.

54. Mao JT, Goldin JG, Dermand J, et al. A pilot study of all-trans-retinoic acid for the treatment of human emphysema. Am J Respir Crit Care Med. 2002;165(5):718-723.

55. Roth MD, Connett JE, D'Armiento JM, et al. Feasibility of retinoids for the treatment of emphysema study. Chest. 2006;130(5):1334-1345.

56. Omori K, Tada Y, Suzuki T, et al. Clinical application of in situ tissue engineering using a scaffolding technique for reconstruction of the larynx and trachea. Ann Otol Rhinol Laryngol. 2008;117(9):673-678.

57. Urita Y, Komuro H, Chen G, Shinya M, Saihara R, Kaneko M. Evaluation of diaphragmatic hernia repair using PLGA mesh-collagen sponge hybrid scaffold: An experimental study in a rat model. Pediatr Surg Int. 2008;24(9):1041-1045.

58. Omori K, Nakamura T, Kanemaru S, Magrufov A, Yamashita M, Shimizu Y. In situ tissue engineering of the cricoid and trachea in a canine model. Ann Otol Rhinol Laryngol. 2008;117(8):609-613.

59. Macchiarini P, Jungebluth $P$, Go $T$, et al. Clinical transplantation of a tissue-engineered airway. Lancet. 2008;372(9655):2023-2030.

60. Tomei AA, Boschetti F, Gervaso F, Swartz MA. 3D collagen cultures under well-defined dynamic strain: A novel strain device with a porous elastomeric support. Biotechnol Bioeng. 2009;103(1):217-225.

61. Mondrinos MJ, Koutzaki S, Lelkes PI, Finck CM. A tissue-engineered model of fetal distal lung tissue. Am J Physiol Lung Cell Mol Physiol. 2007;293(3):L639-L650.

62. Andrade CF, Wong AP, Waddell TK, Keshavjee S, Liu M. Cell-based tissue engineering for lung regeneration. Am J Physiol Lung Cell Mol Physiol. 2007;292(2):L510-L518.
63. Kotton DN, Ma BY, Cardoso WV, et al. Bone marrow-derived cells as progenitors of lung alveolar epithelium. Development. $2001 ; 128(24): 5181-5188$

64. Sueblinvong V, Loi R, Eisenhauer PL, et al. Derivation of lung epithelium from human cord blood-derived mesenchymal stem cells. Am J Respir Crit Care Med. 2008;177(7):701-711.

65. Loi R, Beckett T, Goncz KK, Suratt BT, Weiss DJ. Limited restoration of cystic fibrosis lung epithelium in vivo with adult bone marrow-derived cells. Am J Respir Crit Care Med. 2006;173(2):171-179.

66. Theise ND, Henegariu O, Grove J, et al. Radiation pneumonitis in mice: A severe injury model for pneumocyte engraftment from bone marrow. Exp Hematol. 2002;30(11):1333-1338.

67. Kotton DN, Fabian AJ, Mulligan RC. Failure of bone marrow to reconstitute lung epithelium. Am J Respir Cell Mol Biol. 2005;33(4): 328-334.

68. Weiss DJ, Kolls JK, Ortiz LA, Panoskaltsis-Mortari A, Prockop DJ. Stem cells and cell therapies in lung biology and lung diseases. Proc Am Thorac Soc. 2008;5(5):637-667.

69. Dominici M, Le Blanc K, Mueller I, et al. Minimal criteria for defining multipotent mesenchymal stromal cells. The International Society for Cellular Therapy position statement. Cytotherapy. 2006;8(4): 315-317.

70. Ventura C, Cantoni S, Bianchi F, et al. Hyaluronan mixed esters of butyric and retinoic acid drive cardiac and endothelial fate in term placenta human mesenchymal stem cells and enhance cardiac repair in infarcted rat hearts. J Biol Chem. 2007;282(19):14243-14252.

71. Sueblinvong V, Weiss DJ. Cell therapy approaches for lung diseases: Current status. Curr Opin Pharmacol. 2009;9(3):268-273.

72. Ortiz LA, Dutreil M, Fattman C, et al. Interleukin 1 receptor antagonist mediates the antiinflammatory and antifibrotic effect of mesenchymal stem cells during lung injury. Proc Natl Acad Sci USA. 2007;104(26):11002-11007.

73. Gupta N, Su X, Popov B, Lee JW, Serikov V, Matthay MA. Intrapulmonary delivery of bone marrow-derived mesenchymal stem cells improves survival and attenuates endotoxin-induced acute lung injury in mice. J Immunol. 2007;179(3):1855-1863.

74. Xu J, Woods CR, Mora AL, et al. Prevention of endotoxin-induced systemic response by bone marrow-derived mesenchymal stem cells in mice. Am J Physiol Lung Cell Mol Physiol. 2007;293(1):L131-L141.

75. Mei SH, McCarter SD, Deng Y, Parker CH, Liles WC, Stewart DJ. Prevention of LPS-induced acute lung injury in mice by mesenchymal stem cells overexpressing angiopoietin 1. PLoS Med. 2007;4(9):e269.

76. Health USNIo. http://clinicaltrials.gov. Vol 20092008.

77. Taupin P. OTI-010 Osiris Therapeutics/JCR Pharmaceuticals. Curr Opin Investig Drugs. 2006;7(5):473-481.

78. Osiris. Osiris Therapeutics Reports interim data for COPD stem cell study 2009. Available from: http://investor.osiris.com/releases.cfm?Yea $\mathrm{r}=\&$ ReleasesType $=\&$ DisplayPage $=2$. Accessed on February 10, 2010.
International Journal of COPD

\section{Publish your work in this journal}

The International Journal of COPD is an international, peer-reviewed journal of therapeutics and pharmacology focusing on concise rapid reporting of clinical studies and reviews in COPD. Special focus is given to the pathophysiological processes underlying the disease, intervention programs, patient focused education, and self management protocols.

\section{Dovepress}

This journal is indexed on PubMed Central, MedLine and CAS. The manuscript management system is completely online and includes a very quick and fair peer-review system, which is all easy to use. Visit http://www.dovepress.com/testimonials.php to read real quotes from published authors. 